\title{
Large Scale Synthesis of Green Synthesized Zinc Oxide Nanoparticles from Banana Peel Extracts and Their Inhibitory Effects against Colletotrichum sp., Isolate KUFC 021, Causal Agent of Anthracnose on Dendrobium Orchid
}

\author{
Nattanan Panjaworayan T-Thienprasert $\mathbb{D}^{1},{ }^{1}$ Jiraroj T-Thienprasert $\mathbb{D},{ }^{2,3}$ \\ Jittiporn Ruangtong $\mathbb{D},{ }^{1}$ Thitiradsadakorn Jaithon $\mathbb{D}^{1},{ }^{1}$ Pattana Srifah Huehne $\mathbb{D}^{4}{ }^{4}$ \\ and Onuma Piasai $\mathbb{D}^{5}$ \\ ${ }^{1}$ Department of Biochemistry, Faculty of Science, Kasetsart University, 50 Ngamwongwan Rd. Ladyao, Chatujak 10900, Thailand \\ ${ }^{2}$ Department of Physics, Faculty of Science, Kasetsart University, 50 Ngamwongwan Rd. Ladyao, Chatujak 10900, Thailand \\ ${ }^{3}$ Thailand Center of Excellence in Physics, Ministry of Higher Education, Science, Research and Innovation, 328 Si Ayutthaya Road, \\ Bangkok 10400, Thailand \\ ${ }^{4}$ Research Laboratory of Biotechnology, Chulabhorn Research Institute, Vibhavadi Rd., Laksi, Bangkok 10210, Thailand \\ ${ }^{5}$ Department of Plant Pathology, Faculty of Agriculture, Kasetsart University, Bangkok 10900, Thailand
}

Correspondence should be addressed to Nattanan Panjaworayan T-Thienprasert; fscinnp@ku.ac.th

and Onuma Piasai; agromj@ku.ac.th

Received 6 July 2021; Revised 4 September 2021; Accepted 17 September 2021; Published 13 October 2021

Academic Editor: Leander Tapfer

Copyright (c) 2021 Nattanan Panjaworayan T-Thienprasert et al. This is an open access article distributed under the Creative Commons Attribution License, which permits unrestricted use, distribution, and reproduction in any medium, provided the original work is properly cited.

Fungicides have been extensively used to control fungal diseases that affect several crops including ornamental crops. However, concerns have arisen due to a development of fungicide resistance and increasing incidences of fungicide toxicity effects on nontarget organisms. As zinc oxide nanoparticles ( $\mathrm{ZnO} \mathrm{NPs}$ ) have demonstrated effective antimicrobial activity, this study is therefore aimed at synthesizing $\mathrm{ZnO}$ NPs from banana peels using a green chemistry method in a large scale and determines their physical properties including their inhibitory effects against a plant pathogen fungus causing anthracnose in orchids, Colletotrichum sp. Results from X-ray diffraction and scanning electron microscope indicated that the synthesized ZnO NPs were obtained without other crystalline impurities, and they were spherical in shape with the average diameter of $256 \pm 40 \mathrm{~nm}$, respectively. The absorption peak was found to be centered at $\sim 370 \mathrm{~nm}$ with the optical band gap value approximately $2.8 \mathrm{eV}$. Fourier transform infrared spectroscopy analysis confirmed the presence of several functional groups on synthesized $\mathrm{ZnO}$ NPs. The total amount of synthesized ZnO NPs was obtained about $170 \mathrm{~g}$ for a synthesis reaction. By performing the antifungal activity assay, high doses of green synthesized ZnO NPs significantly inhibited growth of isolated Colletotrichum sp. (KUFC 021) on culture plates. Under greenhouse conditions, high doses of synthesized ZnO NPs also significantly reduced anthracnose symptoms on inoculated orchid leaves with the Colletotrichum sp. (KUFC 021).

\section{Introduction}

Zinc oxide nanoparticles ( $\mathrm{ZnO} \mathrm{NPs}$ ) have been shown to efficiently control microbial growth [1]. They are cheaper than silver nanoparticles with very high photocatalytic efficiency [2] and more biocompatible than other inorganic photocatalytic materials such as titanium dioxide [3]. Therefore, they are popularly employed as an active antimicrobial agent in food packaging [4], in the textile industry [5], paints [6], and plastics [7].

In recent decades, green synthesis of nanoparticles has gained extensive attention because it is environmentally friendly, reliable, and cost-effective and does not require high 
pressure or high energy [8]. Principally, the green synthesis of nanoparticles can be achieved by addition of reducing agents and/or metal capping agents such as flavonoids, phenols, enzymes, and aldehydes $[9,10]$ present in plants or microorganisms, including animals [11]. Several studies have reported successful synthesis of green synthesized $\mathrm{ZnO}$ NPs with antibacterial activity from different bioresources, for example, plants [12-14], microbes [15], algae [16], and biowastes such as vegetable peel [17], orange fruit peel [18], banana peels [19], and durian rind [20]. In addition, biosynthesis of $\mathrm{ZnO}$ NPs has also been conducted on their antifungal activity. For example, spherical ZnO NPs synthesized by Aspergillus terreus were reported to strongly inhibit against Aspergillus niger (causing black mold disease on some fruits), Aspergillus fumigatus (causing aspergillosis in human), and Aspergillus aculeatus (a causal agent of plant disease) [21]. Furthermore, green synthesis of ZnO NPs using flower extract of Nyctanthes arbortristisshowed to have efficient antifungal activity toward Alternaria alternata (causing leaf spot in plants), Aspergillus niger, Botrytis cinerea (causing grey mould rot), Fusarium oxysporum (rotting agent in plants), and Penicillium expansum (causing blue mould) [22]. Subsequently, green synthesized $\mathrm{ZnO}$ NPs have been demonstrated as high-potential antifungal agents against plant pathogenic fungi.

Colletotrichum spp. is the most common causal agents of postharvest disease known as anthracnose. It widely infects several tropical fruits $[23,24]$, a wide range of plants and vegetables [25] including an ornamental crop such as orchids $[26,27]$. Infection of Colletotrichum sp. on orchids such as $C$. gloeosporioides [28] or C. boninense [29] causes depressed circular leaf spots known as anthracnose spots or the necrotic lesions leading to plant defoliation and death in severe cases. Hence, orchids anthracnose by Colletotrichumspp. has caused significance in production losses $[28,30]$. Although anthracnose is mostly controlled based on fungicide treatment, Colletotrichumspp. has been reported to have the ability to develop resistance to fungicides in some crops [31-33]. Therefore, it is crucial to find alternative managements to control infection of the plant pathogenic fungi such as Colletotrichum sp.

This study is therefore aimed at synthesizing ZnO NPs by a green chemistry using crude extraction of banana peels (Musa sapientum) in a large scale synthesis. Physical properties of synthesized $\mathrm{ZnO}$ NPs were then characterized for their structures, morphology, and absorption spectrum by using $\mathrm{X}$ ray diffraction (XRD), scanning electron microscope (SEM), and UV-visible spectrophotometer, respectively. Moreover, the surface chemistry of nanoparticles was also analyzed using the Fourier-transform infrared (FTIR) spectrometer. Furthermore, antifungal activity of synthesized $\mathrm{ZnO}$ NPs against Colletotrichumspp. that infected Dendrobium sp. (Sonia Earsakul) [34] was also determined both in the in vitro assay and greenhouse tests.

\section{Materials and Methods}

2.1. Preparation of Banana Peel Crude Extract. Peels of medium ripe banana (Musa sapientum) were prepared as previously described in Ruangtong et al. [19]. In this study, $400 \%(\mathrm{w} / \mathrm{v})$ of crude extract was prepared by extracting $3,200 \mathrm{mg}$ of grounded banana peels in $800 \mathrm{~mL}$ of distilled water at room temperature for $1 \mathrm{~h}$ under constant stirring (VELP Scientifica). Next, crude extracts were filtered twice using filter cloth and then stored at $4^{\circ} \mathrm{C}$ until further use.

\subsection{A Large Scale Synthesis of ZnO NPs by a Green Chemistry} Using Banana Peel Extract. Firstly, $800 \mathrm{~mL}$ of $2 \mathrm{M}$ zinc acetate solution (Ajax Finechem) was prepared using deionized water. Then, it was mixed with $800 \mathrm{~mL}$ of $400 \%$ (w/v) of banana peel crude extract at $30^{\circ} \mathrm{C}$ under constant stirring using a magnetic stirrer (VELP Scientifica). After $1 \mathrm{~h}$, the mixture was adjusted to $\mathrm{pH} 12$ with $10 \mathrm{M}$ of $\mathrm{NaOH}$ solution. Next, the precipitants were filtered using a Whatman filter paper, grade 4 (GE Healthcare), then dried in a hot oven (Kelvitron ${ }^{\circledR}$ ) at $80^{\circ} \mathrm{C}$ overnight. Finally, white powder was collected, washed several times with distilled water, and further heated in a hot oven at $80^{\circ} \mathrm{C}$ until dried. This green synthesis was independently performed three times. For each synthesis, mass of obtained powder was measured twice using a four-digit analytical balance (Thomas Scientific).

2.3. X-Ray Diffractometer (XRD). X-ray diffraction patterns were recorded using an X-ray diffractometer (Bruker d8 Advance) using $\mathrm{Cu} K$ radiation of wavelength $=0.1541 \mathrm{~nm}$ in the scan range $2=20-80^{\circ}$. Phase search was then compared using $\mathrm{ZnO}$ wurtzite JCPDS number 00036-1451 [35].

2.4. UV-VIS Spectroscopy. The optical absorption spectra of synthesized $\mathrm{ZnO}$ dispersed in water (about $500 \mu \mathrm{g} / \mathrm{mL}$ ) were recorded using the UV-VIS spectrophotometer (SHIMADZU). The measurement spectrums ranged between 300 and $600 \mathrm{~nm}$. Next, the optical band gap of $\mathrm{ZnO}$ was determined using the Tauc plot [36].

2.5. Scanning Electron Microscope (SEM). Prior to analysis, green synthesized $\mathrm{ZnO}$ particles were mounted on aluminum stubs and coated with gold film. Visualization of $\mathrm{ZnO}$ morphology was performed using a SEM (FEI). The size of particles was then analyzed using the ImageJ program [37].

2.6. Fourier Transform Infrared Spectroscopy (FTIR) Analysis. Grounded banana peels and synthesized $\mathrm{ZnO}$ NPs were analyzed using a Vertex 70, Platinum ATR (Bruker) by collecting spectra at room temperature under atmospheric pressure, at an average of 32 scans with a resolution of $4 \mathrm{~cm}^{-1}$. The ATR mode was performed from 200 to $4,000 \mathrm{~cm}^{-1}$. The IR spectrum table (Merck) was then used to determine functional groups and compound class.

2.7. Fungal Isolation. Symptomatic orchid plants, Dendrobium sp. (Sonia Earsakul), were collected in June 2020 to determine the causal agent. Fungal isolation from orchid leaves was carried out according to technique tissue transplanting described in Agrios (2005) [38]. In detail, infected leaves were cut into $0.5 \mathrm{~cm} \times 0.5 \mathrm{~cm}$, thoroughly cleaned and immersed in a solution containing $10 \%$ of $\mathrm{NaOCl}$ (The Clorox ${ }^{\circledR}$ Company, Jiangsu China) for $3 \mathrm{~min}$. The leaves were rinsed with sterile distilled water (SDW) twice and dried on sterile filter paper. Next, the leaves were placed on a potato dextrose agar (PDA; Difco Oxford, UK) and incubated at $25 \pm 2^{\circ} \mathrm{C}$ until the mycelium was developed on 
the infected leaves. The mycelium was then subcultured to fresh PDA to obtain pure cultures for identification.

2.8. Identification and Characterization of Colletotrichum sp. Three isolates of Colletotrichum sp. including KUFC 021, KUFC 022, and KUFC 023 were obtained, the cultures were grown on PDA for 7 days at $25 \pm 2^{\circ} \mathrm{C}$. The macroscopic features of the fungi were observed, such as colony color, growth rate, fungal pigment production, and fruiting body. The microscopic characteristics such as acervuli and conidial features were examined under stereo (Olympus, Tokyo, Japan) and compound (Carl Zeiss, Jena, Germany) and compared with the features in identification keys and species descriptions [39].

2.9. Pathogenicity Test. Based on the sporulation, the Colletotrichum sp. isolate KUFC 021 was selected for pathogenic testing on three five-month-old dendrobium plants in a greenhouse. Five leaves wounded with needles were inoculated by spraying with a conidial suspension of $10^{6}$ conidia/mL prepared from the isolate. Plants inoculated with SDW served as control. The inoculated plants were incubated in a moist chamber at $25 \pm 2^{\circ} \mathrm{C}$ for $48 \mathrm{~h}$ and then maintained for 7 days in a greenhouse for symptom evaluation [26].

2.10. Antifungal Activity In Vitro Test of Green Synthesized $\mathrm{ZnO} N$ NS. In the antifungal activity of green synthesized ZnO NPs to control Colletotrichum sp., isolate KUFC 021 was tested in triplicate in vitro on PDA. Mycelial disks $(5 \mathrm{~mm}$ in diameter removed from the margins of 7 days old cultures) were transferred to PDA amended with $\mathrm{ZnO}$ NPs at six different concentrations $(5,000,7,500,12,500$, $15,000,17,500$, and $20,000 \mathrm{mg} / \mathrm{L}$ ). The experiment was conducted by including the negative control agar plate (no $\mathrm{ZnO}$ NPs) and two positive controls, which were PDA plates containing a contact fungicide (mancozeb $80 \% \mathrm{~W} / \mathrm{W} \mathrm{WP}$, Corteva Ltd., Thailand) and a systemic fungicide (carbendazim 50\% W/W WP, Erawan Ltd., Thailand). Five replicate plates of PDA per treatment were incubated at $25 \pm 2^{\circ} \mathrm{C}$. Antimicrobial activity was evaluated by measuring the colony diameter at 7 and 14 days after incubation. The percentage of mycelial growth inhibition was calculated as $(A-B / A) \times 100$, where $A$ and $B$ are the diameter of a fungal colony grown in a negative control plate and the diameter of a fungal colony grown in a plate containing synthesized $\mathrm{ZnO}$ $\mathrm{NPs}$, respectively. Then, the $\mathrm{EC}_{50}$ values of $\mathrm{ZnO}$ NPs against Colletotrichum sp. (KUFC 021) were calculated using GraphPad QuickCalcs (GraphPad software).

2.11. Greenhouse Evaluation of Antifungal Activity from Green Synthesized ZnO NPs. The effectiveness of green synthesized $\mathrm{ZnO}$ NPs was evaluated for the control of anthracnose disease of orchids in vivo. One-hundred and twenty of Dendrobium sp. (Sonia Earsakul) were planted in the greenhouse and arranged in a completely randomized design (CRD) for six treatments (positive control, negative control, $1 \mathrm{~g} / \mathrm{L}$ of carbendazim, $1.5 \mathrm{~g} / \mathrm{L}$ of mancozeb, $20 \mathrm{~g} / \mathrm{L}$ of $\mathrm{ZnO}$ $\mathrm{NPs}$, and $30 \mathrm{~g} / \mathrm{L}$ of $\mathrm{ZnO} \mathrm{NPs}$ ) with twenty replications per treatment. Five treatments were sprayed with a spore suspension of Colletotrichum sp. (KUFC 021) at $10^{8}$ conidia/mL while the negative control was sprayed with water. Plants were then covered with plastic bags for 24 hours. The plastic bags were removed after inoculation, and two different concentrations of green synthesized $\mathrm{ZnO}$ $\mathrm{NPs}$ at 20 and $30 \mathrm{~g} / \mathrm{L}$ were applied to orchid plants and compared to $1 \mathrm{~g} / \mathrm{L}$ carbendazim and $1.5 \mathrm{~g} / \mathrm{L}$ mancozeb utilizing foliar sprays. For positive control, the plants were sprayed with water. The percentage of disease severity index and level of disease [40] was calculated at 7 and 14 days after application. Disease severity was scored on a 1 to 5 scale, where level 1 indicates no infection, healthy; level 2 indicates infection $1-10 \%$, and the leaves area shows necrotic lesions; level 3 indicates infection $11-20 \%$, and the leaves area shows dark brown lesions with acervuli; level 4 indicates infection $21-50 \%$, and the leaves area shows dark brown lesions/lesions that coalesce to form enlarged legion, and level 5 indicates infection greater than $50 \%$, heavily infected leaf turning completely brown and forming several concentric rings.

2.12. Statistical Analysis. Data were analyzed using SPSS (version 22) statistical software. The effect of different concentrations of synthesized $\mathrm{ZnO}$ NPs on the growth of fungi was evaluated by one-way analysis of variance (ANOVA). Duncan's multiple range test was used to compare the differences among treatments. $P$ values less than 0.05 were considered statistically significant.

\section{Results}

3.1. Physical Characteristics of Green Synthesized ZnO NPs from Banana Peel Extract in a Large Scale Synthesis. This study was designed to simplify a green synthesis of $\mathrm{ZnO}$ NPs without requirement of a laboratory centrifuge or microwave and aimed to obtain high yield of $\mathrm{ZnO}$ NPs. By conducting three independent syntheses, a white powder was obtained in each synthesis with the average amount of $177.25 \pm 8.17 \mathrm{~g}$. All three syntheses offered high crystallinity of $\mathrm{ZnO}$ and zincite (JCPDS No. 00-036-1451) without other crystalline impurities as demonstrated in a representative XRD spectrum (Figure 1(a)). An illustrative SEM image shows that most of the synthesized $\mathrm{ZnO}$ were spherical and short oval shapes with the average diameter of $256 \pm$ $40 \mathrm{~nm}$ (Figure 1(b)). The optical property of the synthesized $\mathrm{ZnO}$ NPs was then studied using UV-visible spectroscopy. As a result, the dispersed $\mathrm{ZnO}$ NPs in deionized water shows the absorption peak centered at $\sim 370 \mathrm{~nm}$ (Figure 1(c)). By using the Tauc plot [36], the calculated optical band gap value was found to be $\sim 2.8 \mathrm{eV}$. In addition, the FTIR spectrum indicates the presence of several functional groups on the green synthesized $\mathrm{ZnO}$ NPs (Figure 1(d)). The characteristic peaks obtained between 600 and $450 \mathrm{~cm}^{-1}$ confirms the $\mathrm{Zn}-\mathrm{O}$ stretching bonds, whereas the peak at $3427 \mathrm{~cm}^{-1}$ belongs to the $\mathrm{O}-\mathrm{H}$ stretch of the carboxylic acid group that was found in both $\mathrm{ZnO}$ NPs and banana peels. Moreover, the peaks at $1638 \mathrm{~cm}^{-1}, 1536 \mathrm{~cm}^{-1}$, and $1407 \mathrm{~cm}^{-1}$ of synthesized $\mathrm{ZnO}$ NPs correspond to $\mathrm{C}=\mathrm{C}$ stretching, $\mathrm{N}-\mathrm{O}$ stretching, and $\mathrm{O}-\mathrm{H}$ bending, respectively (Figure $1(\mathrm{~d})$ ). 


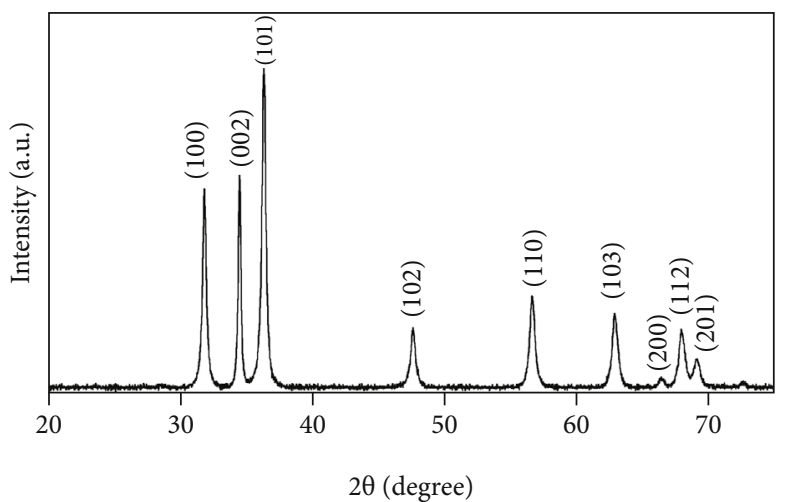

(a)

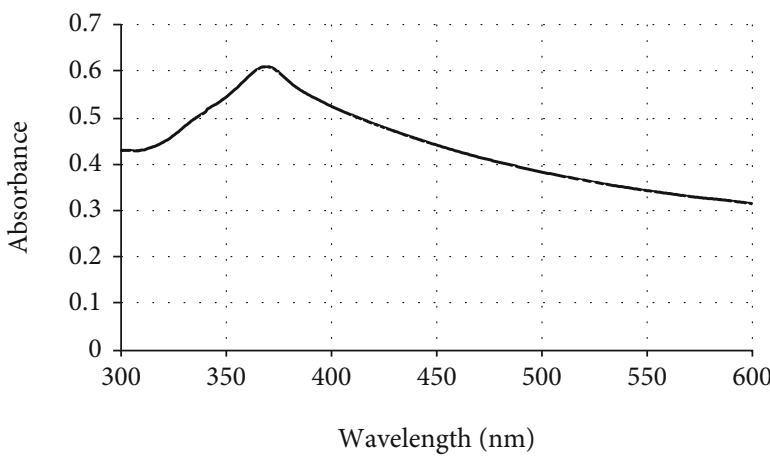

(c)

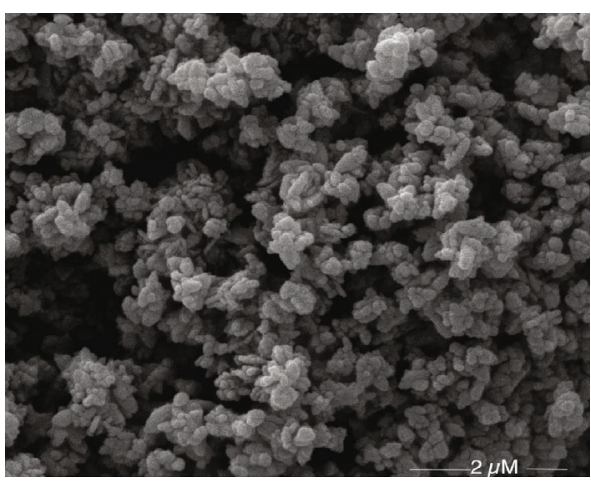

(b)

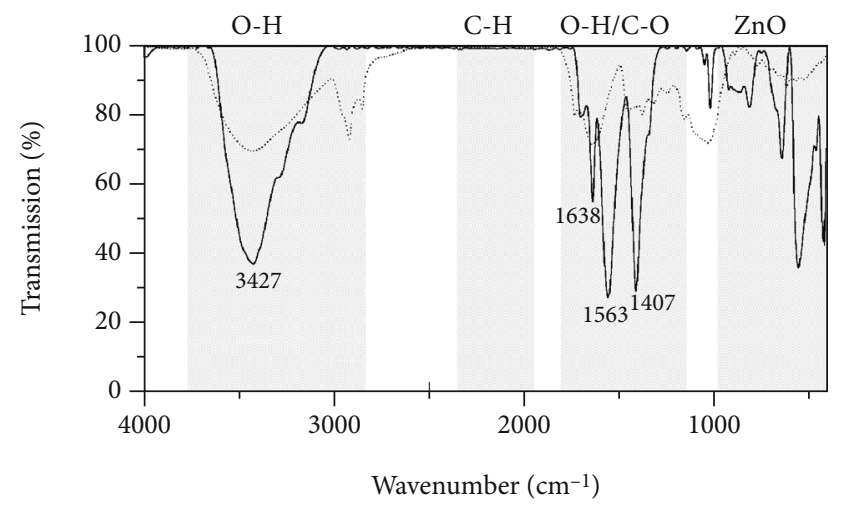

Banana extract

- ZnONPs

FIGURE 1: Physical properties of green synthesized ZnO NPs from banana peels: (a) XRD analysis, (b) SEM image, (c) UV-vis spectrum, and (d) FT-IR spectrum.

3.2. Characterization of Colletotrichum sp. Isolates Causing Anthracnose of Orchids. Three isolates of fungi including KUFC 021, KUFC 022, and KUFC 023 were obtained from infected leaves of Dendrobium sp. (Sonia Earsakul) with anthracnose symptoms such as numerous black blemishes across the leaf and leaf tips turning brown (Figure 2(a)). Subsequently, both cultural and morphological characteristics were examined. After 7 days, the colony color of the isolates was taupe with average diameter of $8.5-9 \mathrm{~cm}$ (Figure 2(b)). Cylindrical conidia were produced inside the black acervuli that was filled with orange spore masses (Figure 2(c)). Setae was also produced and found to be acicular with dark brown color (Figure 2(d)) while appressoria were ovoid to slightly irregular in shape and had dark brown color (Figure 2(e)). Spores had rod-shape and colorless ranging from $12-17 \times 3-6 \mu \mathrm{m}$ in size (Figure 2(f)). Taken all together, morphological characterization suggested that all isolates were Colletotrichum sp. To confirm Colletotrichum species, molecular characterization is required for a future experiment.

In addition, a pathogenicity test was performed. Dark brown lesions developed on margin of leaves. On the lesion, salmon-colored conidial masses formed concentrically, which resembled symptoms that occurred in the field, were observed on leaves at 7 to 10 days after inoculation, while these symptoms did not occur in the control plants (data not shown). The same fungus was reisolated from the inoculated plants. Pathogenicity test revealed that the isolates of Colletotrichum sp. (KUFC 021) were pathogenic to Dendrobium sp. (Sonia Earsakul), thus satisfying Koch's postulates.

\subsection{A Large Scale Synthesis of ZnO NPs from Banana Peels} Possessed Antifungal Activity against Colletotrichum sp. (KUFC 021) In Vitro. To study antifungal activity of green synthesized $\mathrm{ZnO}$ NPs against Colletotrichum sp. (KUFC 021), inhibitory effects of different concentrations of dispersed $\mathrm{ZnO}$ NPs in deionized water on the fungal growth were analyzed in different time points. From Figure 3, the radial growth of Colletotrichum sp. (KUFC 021) was significantly demolished by $1,000 \mathrm{mg} / \mathrm{mL}$ (manufacturer-recommended dose) of the commercial systemic fungicide and carbendazim in all time points. In contrast, $1,000 \mathrm{mg} / \mathrm{mL}$ of both mancozeb (the commercial contact fungicide) and the synthesized $\mathrm{ZnO}$ NPs could not inhibit the fungal growth at any time points. However, $4,000 \mathrm{mg} / \mathrm{mL}$ of $\mathrm{ZnO}$ 


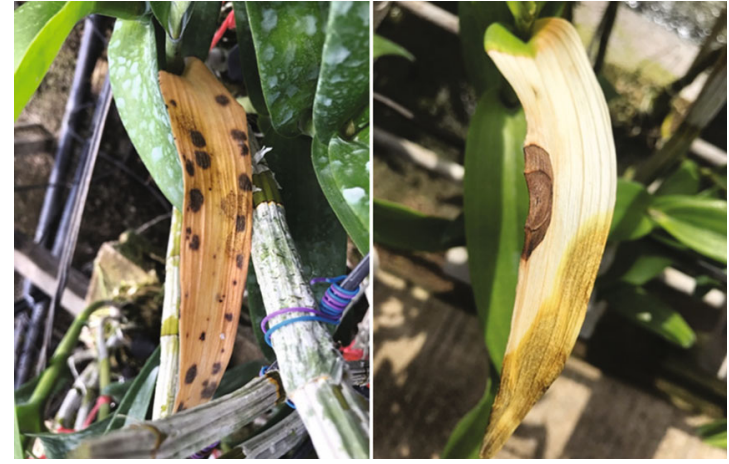

(a)

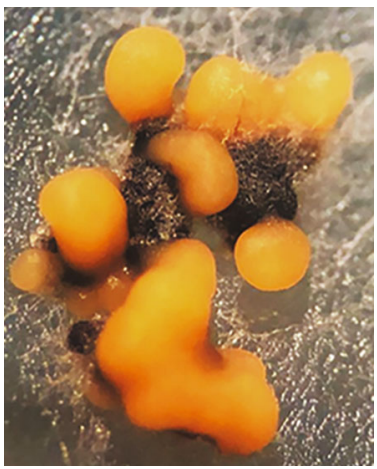

(c)

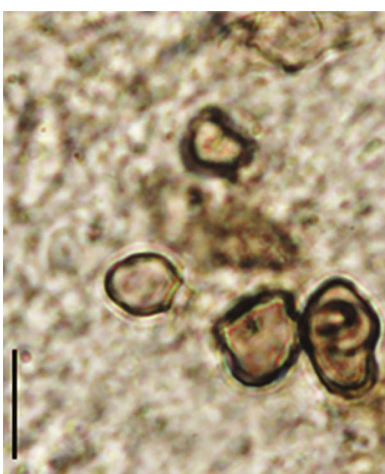

(e)

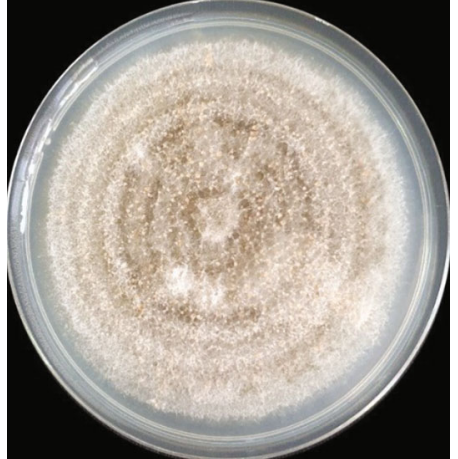

(b)

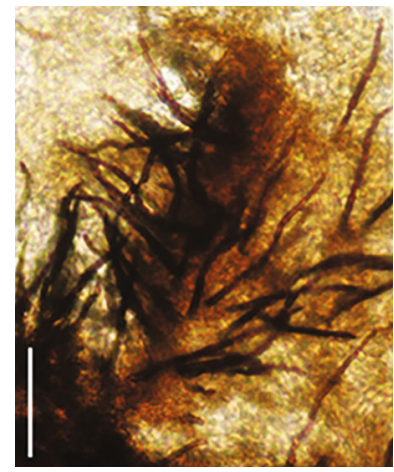

(d)

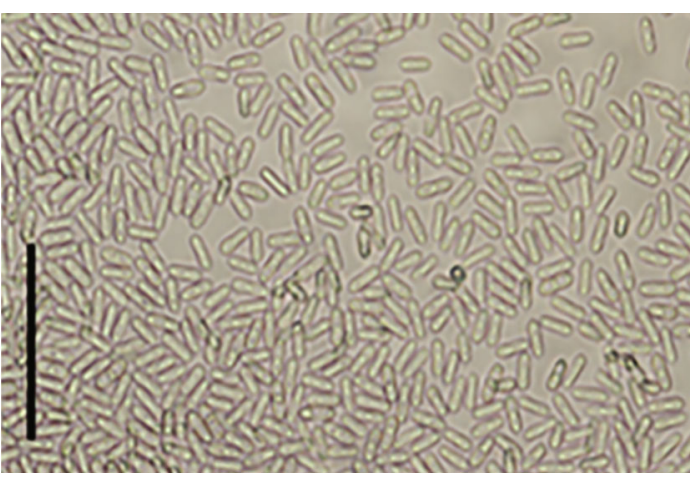

(f)

FIgURE 2: Characterization of an isolated fungus, Colletotrichum sp. (KUFC 021) causing anthracnose of orchid, Dendrobium sp. (Sonia Earsakul) (a) infected leaves with anthracnose symptoms, (b) colony on PDA plates, (c) acervulus, (d) setae, (e) appresoria, (f) conidia. Scale bar for $(\mathrm{d}, \mathrm{f})=20 \mu \mathrm{M}$ and $(\mathrm{e})=5 \mu \mathrm{M}$.

NPs moderately inhibited growth of Colletotrichum sp. (KUFC 021 ) on day 7 , and the effects were slightly reduced on day 10 and day 14.

Next, the antifungal activity assay was further conducted using higher concentrations of $\mathrm{ZnO}$ NPs to determine the effective control to $50 \%$ growth inhibition $\left(\mathrm{EC}_{50}\right)$ against the growth of Colletotrichum sp. isolate KUFC 021. As a result, the antifungal activity of the synthesized $\mathrm{ZnO}$ NPs was exhibited in a dose-dependent manner. The best inhibitory effect was observed on day 7 with the $\mathrm{EC}_{50}$ value equaling 13,991.6 mg/mL (Figure 4). Then, their effect was found to be slightly decreased on day $9\left(\mathrm{EC}_{50}\right.$ values $=$ $14215.4 \mathrm{mg} / \mathrm{mL}$ ). On the other hand, the least inhibition was shown on day $3\left(\mathrm{EC}_{50}=17,717.5 \mathrm{mg} / \mathrm{mL}\right)$. Therefore, the results implied the optimal concentration and time for treatment of $\mathrm{ZnO}$ NPs against Colletotrichum sp. (KUFC 021).

3.4. Effects of Synthesized ZnO NPs from Banana Peels on Growth of Colletotrichum sp. (KUFC 021) In Vivo. Next, antifungal activity of synthesized $\mathrm{ZnO}$ NPs was evaluated in vivo. From Figure 5, the typical symptom of anthracnose was clearly developed on leaves of the positive control (+control) that were inoculated with the Colletotrichum sp. (KUFC 021) suspension on both time points. On the other hand, the negative control plants (-control) without fungal inoculation remained with healthy leaves. Under the greenhouse condition, treated orchid plants with synthesized 


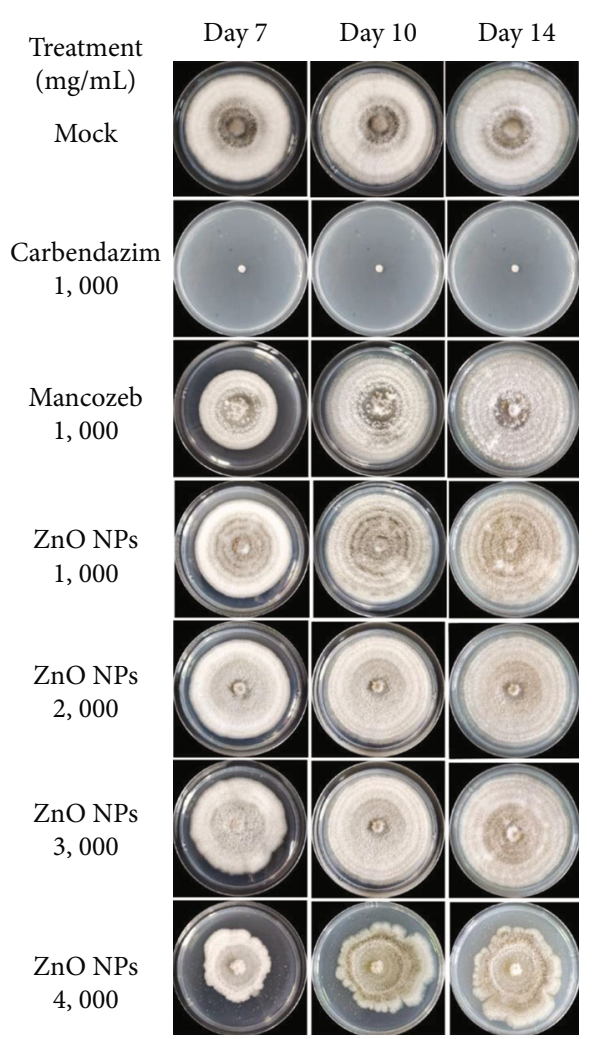

Figure 3: Inhibitory effects of synthesized $\mathrm{ZnO}$ NPs against growth of Colletotrichum sp. (KUFC 021) on PDA plates.

$\mathrm{ZnO}$ NPs showed less disease symptoms on their leaves as same as carbendazim and mancozeb.

Calculation of the level of disease and percentage of disease severity index confirmed that the treatment of $30 \mathrm{~g} / \mathrm{L}$ of the synthesized $\mathrm{ZnO}$ NPs were comparable with the recommended dose of the manufacturer for carbendazim $(1 \mathrm{~g} / \mathrm{L})$ on day 7 and significantly better on day 14 (Table 1). Moreover, effects of synthesized $\mathrm{ZnO}$ NPs were also equivalent to $1.5 \mathrm{~g} / \mathrm{L}$ of mancozeb (Table 1 ).

\section{Discussions}

Synthesis conditions of $\mathrm{ZnO}$ NPs have been reported to significantly affect sizes and shapes of particles that in turn influence their physical and biological properties. The crucial factors include types [41] and concentrations of precursors [19], temperatures [42], and procedure [12]. For the green synthesis, biological entities and their concentrations [43] are also important factors that affect morphology of $\mathrm{ZnO}$ NPs. Previously, we synthesized ZnO NPs from banana peel extract and obtained an average yield of a laboratory scale (0.5-1.0 g) [19]. In this study, we simplified the synthesis procedure by using a filter paper instead of a centrifugation and increased volume of both percussor and banana peel extract. Herein, we obtained approximately a 170-fold increase in the yield of $\mathrm{ZnO}$ NPs without the presence of other crystalline contaminations. Since this study can produce an average of $177 \mathrm{~g}$ per synthesis reaction, this synthesis condition is viable for providing the effective dose for controlling the disease in greenhouses. With the quality control check on the shape and size of $\mathrm{ZnO}$ NPs, the production cost was around $\$ 0.55$ USD. This price is comparable to that of commercial $\mathrm{ZnO} \mathrm{NPs}$ on the market. Moreover, the physical properties of newly synthesized $\mathrm{ZnO}$ NPs including the photoluminescence spectrum and optical bandgap were in accordance with other green synthesized ZnO NPs using different biological extracts [44, 45]. Although the FTIR result also confirmed the functional groups of phytochemicals presented in the banana peel extract as reported previously [19], a modified procedure for this synthesis resulted in the new morphology of $\mathrm{ZnO}$ NPs with round shape about $256 \pm 40 \mathrm{~nm}$.

Numerous studies have shown that green synthesized $\mathrm{ZnO}$ NPs possess potent antibacterial activity while few studies have addressed their antifungal effects. This study firstly evaluated antifungal activity of green synthesized ZnO NPs from banana peel extracts against Colletotrichum sp. Our synthesized $\mathrm{ZnO}$ NPs significantly inhibited growth of Colletotrichum sp. (KUFC 021) and drastically reduced anthracnose symptoms. Despite their inhibitory effects being weaker than that of carbendazim and mancozeb, prolonged inhibitory effects of the synthesized ZnO NPs against Colletotrichum sp. (KUFC 021) were observed in the greenhouse, and it tended to be better than both mancozeb and carbendazim. In addition, toxicity of both carbendazim and mancozeb has raised a serious concern on safety. For example, carbendazim has been reported to induce testicular toxicity and immature spermatids in male rats [46] and even its low dose $(10 \mathrm{mM}$ or $1.91 \mathrm{~g} / \mathrm{L})$ could significantly affect liver and hematology of the mouse model [47]. Similarly, mancozeb has been shown to cause oxidative stress in mammalian cell lines, thyroid disease [48], acute neurotoxic effect, and mitochondrial dysfunction in adult experimental animals [49]. Notably, carbendazim and mancozeb are fungicides that are heavily used to control fungal disease in orchids [50]. Therefore, a development of safe alternative fungicide is crucial. De la Rosa-García et al. (2018) showed that chemical synthesized ZnO NPs (size 26-37 $\mathrm{nm}$ ) by coprecipitation and hydrothermal methods significantly inhibited growth of isolated C. gloeosporioides from avocado with the minimum inhibitory concentration equals to $0.312 \mathrm{mg} / \mathrm{mL}$ on PDA plates [51]. Moreover, Pariona et al. (2020) reported that $1 \mathrm{mg} / \mathrm{mL}$ of chemical synthesized $\mathrm{ZnO}$ NPs with platelet shape (size $\sim 246 \pm 40 \mathrm{~nm}$ ) using a hydrothermal method suppressed growth of C. gloeosporioides on PDA plates by $60 \%$ inhibition that was stronger than $\mathrm{ZnO}$ NPs with rod (size $\sim 780 \times 142 \mathrm{~nm}$ ) and spherical (size $\sim 18$ $\pm 2 \mathrm{~nm}$ ) shapes [52].

In addition, foliar application of $\mathrm{ZnO}$ NPs has been reported to enhance plant growth, fruit yield, and biomass accumulation in various plants such as habanero pepper plants [53], maize [54], wheat [55], and foxtail millet [56]. However, depending on the plant size, plant type, NP concentrations, exposure time, and plant species, NPs might produce phytotoxicity, cytotoxicity, genotoxicity, or oxidative stress in plants $[57,58]$. Although the orchid plants treated with $\mathrm{ZnO}$ NPs appeared to be healthy throughout our experiment, a long-term investigation is needed to determine the impact of green produced $\mathrm{ZnO}$ NPs on orchid plant growth. 


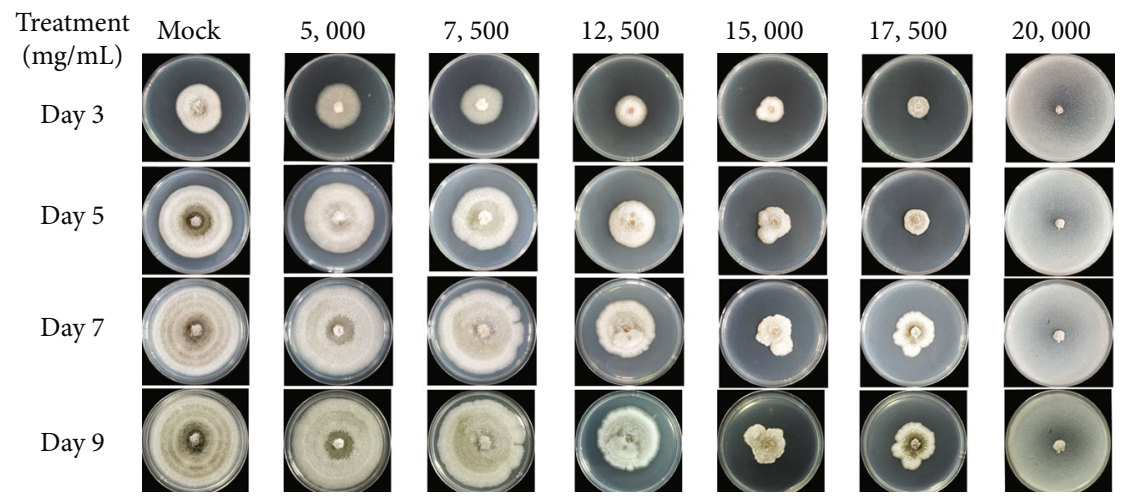

(a)

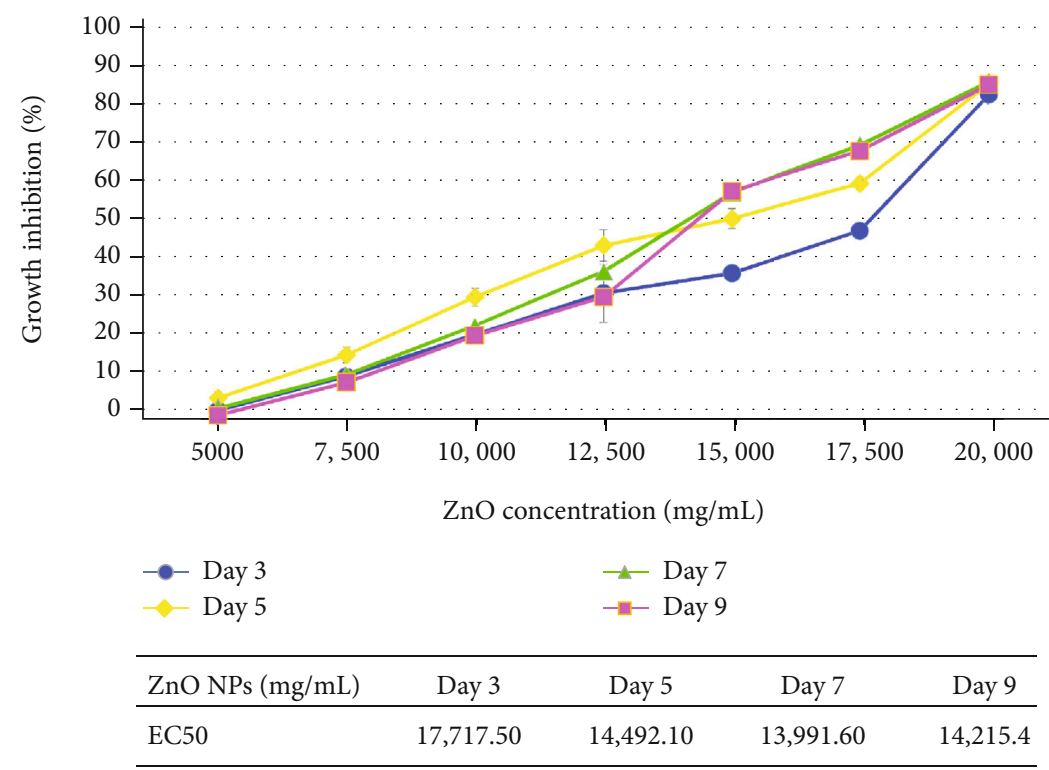

(b)

Figure 4: Antifungal activity of different concentrations of synthesized ZnO NPs against growth of Colletotrichum sp. (KUFC 021). (a) Inhibitory effects on PDA plates at different time points. (b) Quantitative analysis and $\mathrm{EC}_{50}$ values of synthesized ZnO NPs.

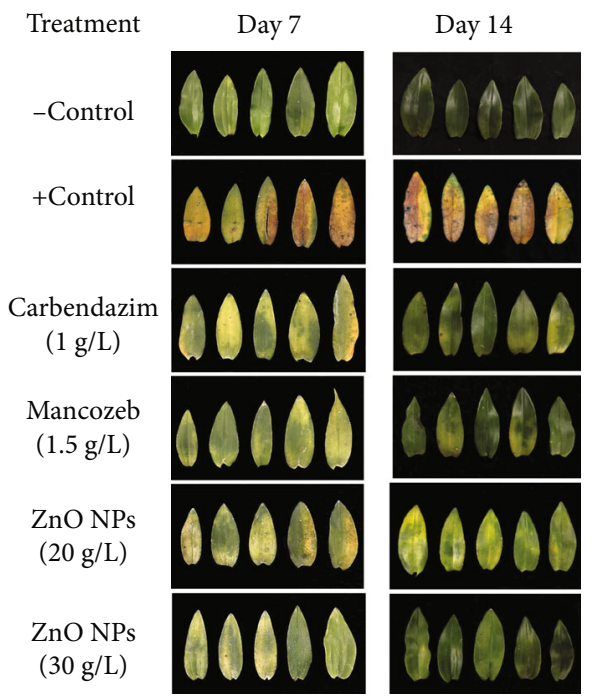

FIGURE 5: Evaluation of antifungal activity of synthesized ZnO NPs on inoculated leaves of orchids with Colletotrichum sp. (KUFC 021) under greenhouse condition.
TABLE 1: Effects of synthesized ZnO NPs against Colletotrichum sp. (KUFC 021) in a greenhouse. Lower case letters represent significant differences determined by ANOVA, followed by Duncan's posthoc test.

\begin{tabular}{lcccc}
\hline \multirow{2}{*}{ Treatment } & \multicolumn{2}{c}{ Level of disease } & \multicolumn{2}{c}{ Disease severity } \\
index (\%) \\
& Day 7 & Day 14 & Day 7 & Day 14 \\
\hline ZnO NPs (20 g/L) & $2.0^{\mathrm{b}}$ & $2.10^{\mathrm{b}}$ & 41 & 45 \\
ZnO NPs (30 g/L) & $1.70^{\mathrm{b}}$ & $1.80^{\mathrm{ab}}$ & 34 & 36 \\
Carbendazim (1 g/L) & $1.75^{\mathrm{b}}$ & $2.10^{\mathrm{b}}$ & 35 & 43 \\
Mancozeb (1.5 g/L) & $1.70^{\mathrm{b}}$ & $1.90^{\mathrm{ab}}$ & 34 & 38 \\
Control (+) & $3.20^{\mathrm{c}}$ & $4.30^{\mathrm{c}}$ & 64 & 86 \\
Control (-) & $1.10^{\mathrm{a}}$ & $1.55^{\mathrm{a}}$ & 22 & 31 \\
\hline
\end{tabular}

Taken together, appropriate morphology of $\mathrm{ZnO}$ NPs may serve as a novel antifungal agent. We are aware that our green synthesized $\mathrm{ZnO}$ NPs require high doses to abolish growth of Colletotrichum sp. We are currently carrying out experiments by using different biomaterials for green 
synthesis with combination of metal doping for improving physical and biological properties of synthesized ZnO NPs.

\section{Conclusion}

This study highlighted a large scale synthesis of $\mathrm{ZnO}$ NPs from banana peel extracts using a green synthesis. The synthesized $\mathrm{ZnO}$ NPs with round shape, size $\sim 256 \pm 40 \mathrm{~nm}$, were obtained without other crystalline impurities and had average energy band gaps $\sim 2.8 \mathrm{eV}$. High doses of the synthesized $\mathrm{ZnO}$ NPs significantly suppressed growth of isolated Colletotrichum sp. (KUFC 021) from orchid plants on the culture plates. Moreover, they drastically reduced anthracnose symptoms on inoculated leaves with Colletotrichum sp. (KUFC 021) in the greenhouse condition.

\section{Data Availability}

Data are available on request.

\section{Conflicts of Interest}

The authors declare that they have no known competing financial interests or personal relationships that could have appeared to influence the work reported in this paper.

\section{Acknowledgments}

This work was supported by the National Research Council of Thailand [Aor-Por-Sor 96/2563].

\section{References}

[1] B. Lallo da Silva, M. P. Abuçafy, E. Berbel Manaia et al., "Relationship between structure and antimicrobial activity of zinc oxide nanoparticles: an overview," International Journal of Nanomedicine, vol. Volume 14, pp. 9395-9410, 2019.

[2] K. G. Chandrappa and T. V. Venkatesha, "Electrochemical synthesis and photocatalytic property of zinc oxide nanoparticles," Nano-Micro Letters, vol. 4, no. 1, pp. 14-24, 2012.

[3] G. D. Venkatasubbu, R. Baskar, T. Anusuya, C. A. Seshan, and R. Chelliah, "Toxicity mechanism of titanium dioxide and zinc oxide nanoparticles against food pathogens," Colloids and Surfaces. B, Biointerfaces, vol. 148, pp. 600-606, 2016.

[4] I. Kim, K. Viswanathan, G. Kasi, S. Thanakkasaranee, K. Sadeghi, and J. Seo, "ZnO nanostructures in active antibacterial food packaging: preparation methods, antimicrobial mechanisms, safety issues, future prospects, and challenges," Food Reviews International, pp. 1-29, 2020.

[5] A. Hatamie, A. Khan, M. Golabi et al., "Zinc oxide nanostructure-modified textile and its application to biosensing, photocatalysis, and as antibacterial material," Langmuir, vol. 31, no. 39, pp. 10913-10921, 2015.

[6] B. Stieberova, M. Zilka, M. Ticha et al., "Application of $\mathrm{ZnO}$ nanoparticles in a self-cleaning coating on a metal panel: an assessment of environmental benefits," ACS Sustainable Chemistry \& Engineering, vol. 5, no. 3, pp. 2493-2500, 2017.

[7] M. Abbas, M. Buntinx, W. Deferme, and R. Peeters, "(Bio)polymer/ZnO nanocomposites for packaging applications: a review of gas barrier and mechanical properties," Nanomaterials (Basel), vol. 9, no. 10, p. 1494, 2019.
[8] J. Singh, T. Dutta, K.-H. Kim, M. Rawat, P. Samddar, and P. Kumar, "Green' synthesis of metals and their oxide nanoparticles: applications for environmental remediation," Journal of Nanobiotechnology, vol. 16, no. 1, p. 84, 2018.

[9] M. Doble and A. K. Kruthiventi, "CHAPTER 3 - catalysis and green chemistry," in Green Chemistry and Engineering, M. Doble and A. K. Kruthiventi, Eds., pp. 53-67, Academic Press, Burlington, 2007.

[10] M. Doble and A. K. Kruthiventi, "CHAPTER 4 - biocatalysis: green chemistry," in Green Chemistry and Engineering, M. Doble and A. K. Kruthiventi, Eds., pp. 69-91, Academic Press, Burlington, 2007.

[11] A. Gour and N. K. Jain, "Advances in green synthesis of nanoparticles," Artificial Cells, Nanomedicine, and Biotechnology, vol. 47, no. 1, pp. 844-851, 2019.

[12] D. Jevapatarakul, J. T-Thienprasert, S. Payungporn, T. Chavalit, A. Khamwut, and N. P. T-Thienprasert, "Utilization of Cratoxylum formosum crude extract for synthesis of $\mathrm{ZnO}$ nanosheets: Characterization, biological activities and effects on gene expression of nonmelanoma skin cancer cell," Biomedicine \& Pharmacotherapy, vol. 130, p. 110552, 2020.

[13] D. Suresh, P. C. Nethravathi, H. R. Udayabhanu, H. Nagabhushana, and S. C. Sharma, "Green synthesis of multifunctional zinc oxide ( $\mathrm{ZnO})$ nanoparticles using Cassia fistula plant extract and their photodegradative, antioxidant and antibacterial activities," Materials Science in Semiconductor Processing, vol. 31, pp. 446-454, 2015.

[14] N. Bala, S. Saha, M. Chakraborty et al., "Green synthesis of zinc oxide nanoparticles using hibiscus subdariffa leaf extract: effect of temperature on synthesis, anti-bacterial activity and antidiabetic activity," RSC Advances, vol. 5, no. 7, pp. 4993-5003, 2015.

[15] A. B. Moghaddam, M. Moniri, S. Azizi et al., "Biosynthesis of $\mathrm{ZnO}$ nanoparticles by a new Pichia kudriavzevii yeast strain and evaluation of their antimicrobial and antioxidant activities," Molecules, vol. 22, no. 6, p. 872, 2017.

[16] S. Azizi, M. B. Ahmad, F. Namvar, and R. Mohamad, "Green biosynthesis and characterization of zinc oxide nanoparticles using brown marine macroalga Sargassum muticum aqueous extract," Materials Letters, vol. 116, pp. 275-277, 2014.

[17] T. V. Surendra, S. M. Roopan, N. A. Al-Dhabi, M. V. Arasu, G. Sarkar, and K. Suthindhiran, "Vegetable peel waste for the production of $\mathrm{ZnO}$ nanoparticles and its toxicological efficiency, antifungal, hemolytic, and antibacterial activities," Nanoscale Research Letters, vol. 11, no. 1, p. 546, 2016.

[18] T. U. Doan Thi, T. T. Nguyen, Y. D. Thi, K. H. Ta Thi, B. T. Phan, and K. N. Pham, "Green synthesis of $\mathrm{ZnO}$ nanoparticles using orange fruit peel extract for antibacterial activities," RSC Advances, vol. 10, no. 40, pp. 23899-23907, 2020.

[19] J. Ruangtong, J. T-Thienprasert, and N. P. T-Thienprasert, "Green synthesized $\mathrm{ZnO}$ nanosheets from banana peel extract possess anti- bacterial activity and anti-cancer activity," Materials Today Communications, vol. 24, p. 101224, 2020.

[20] V. Ravichandran, S. Sumitha, C. Y. Ning et al., "Durian waste mediated green synthesis of zinc oxide nanoparticles and evaluation of their antibacterial, antioxidant, cytotoxicity and photocatalytic activity," Green Chemistry Letters and Reviews, vol. 13, no. 2, pp. 102-116, 2020.

[21] G. Baskar, J. Chandhuru, K. Sheraz Fahad, and A. S. Praveen, "Mycological synthesis, characterization and antifungal 
activity of zinc oxide nanoparticles," Asian J. Pharm. Tech, vol. 3, no. 4, pp. 142-146, 2013.

[22] P. Jamdagni, P. Khatri, and J. S. Rana, "Green synthesis of zinc oxide nanoparticles using flower extract of Nyctanthes arbortristis and their antifungal activity," Journal of King Saud University - Science, vol. 30, no. 2, pp. 168-175, 2018.

[23] Y. Siddiqui and A. Ali, "Chapter 11 - Colletotrichum gloeosporioides (anthracnose)," in Postharvest Decay, S. Bautista-Baños, Ed., pp. 337-371, Academic Press, San Diego, 2014.

[24] A. Vitale, A. C. Alfenas, D. L. Siqueira, D. Magista, G. Perrone, and G. Polizzi, "Cultivar resistance against Colletotrichum asianum in the world collection of mango germplasm in southeastern Brazil," Plants (Basel), vol. 9, no. 2, p. 182, 2020.

[25] P. F. Cannon and C. M. Simmons, "Diversity and host preference of leaf endophytic fungi in the Iwokrama Forest Reserve, Guyana," Journal of mycology, vol. 94, 220 pages, 2002.

[26] M.-J. Park, C.-G. Back, and J.-H. Park, "Colletotrichum cymbidiicola Causing anthracnose on Cymbidium Orchids in Korea," Mycobiology, vol. 48, no. 4, pp. 321-325, 2020.

[27] S. Parthibhan, M. V. Rao, and T. Senthil Kumar, "Culturable fungal endophytes in shoots of Dendrobium aqueum Lindley - An imperiled orchid," Ecological Genetics and Genomics, vol. 3-5, pp. 18-24, 2017.

[28] R. T. McMillan, "Efficacy of fungicides for control of Colletotrichum gloeosporioides on dendrobiums," Proc. Fla. State Hort. Soc., vol. 124, pp. 314-316, 2011.

[29] U. Damm, P. F. Cannon, J. H. Woudenberg et al., “The Colletotrichum boninense species complex," Stud Mycol, vol. 73, pp. 1-36, 2012.

[30] E. Fernández-Herrera, M. E. Rentería-Martínez, I. I. RamírezBustos, S. F. Moreno-Salazar, A. Ochoa-Meza, and D. GuillénSánchez, "Colletotrichum karstii: causal agent of anthracnose of Dendrobium nobilein Mexico Colletotrichum boninense," Canadian Journal of Plant Pathology, vol. 42, no. 4, pp. 514519, 2020.

[31] P. Materatski, C. Varanda, T. Carvalho et al., "Effect of longterm fungicide applications on virulence and diversity of Colletotrichum spp. associated to olive anthracnose," Plants (Basel), vol. 8, no. 9, p. 311, 2019.

[32] J. Guarro, T. E. Svidzinski, L. Zaror, M. H. Forjaz, J. Gené, and O. Fischman, "Subcutaneous hyalohyphomycosis caused by Colletotrichum gloeosporioides," Journal of Clinical Microbiology, vol. 36, no. 10, pp. 3060-3065, 1998.

[33] G. Piccirillo, R. Carrieri, G. Polizzi et al., "In vitro and in vivo activity of QoI fungicides against Colletotrichum gloeosporioides causing fruit anthracnose in Citrus sinensis," Scientia Horticulturae, vol. 236, pp. 90-95, 2018.

[34] P. Boonkorkaew, "List of biodiversity resource: Thai orchid database," in Biodiversity resource inventory development project, in: B.-b.E.D. Office (Ed.), Public Organization, Bangkok, 2010.

[35] R. Jenkins, T. G. Fawcett, D. K. Smith, J. W. Visser, M. C. Morris, and L. K. Frevel, "JCPDS - International centre for diffraction data sample preparation methods in X-ray powder diffraction," Powder Diffraction, vol. 1, no. 2, pp. 51-63, 1986.

[36] J. Tauc, "Optical properties and electronic structure of amorphous Ge and Si," Materials Research Bulletin, vol. 3, no. 1, pp. 37-46, 1968.

[37] C. T. Rueden, J. Schindelin, M. C. Hiner et al., "ImageJ2: ImageJ for the next generation of scientific image data," BMC Bioinformatics, vol. 18, no. 1, p. 529, 2017.
[38] G. N. Agrios, "chapter eleven - Plant Diseases caused by," in Plant Pathology (Fifth Edition), G. N. Agrios, Ed., pp. 385614, Academic Press, San Diego, 2005.

[39] B. C. Sutton, The Coelomycetes. Fungi imperfecti with pycnidia, acervuli and stromata, Commonwealth Mycological Institute, Kew UK, 1980.

[40] K. S. Chiang, H. I. Liu, J. W. Tsai, J. R. Tsai, and C. H. Bock, “A discussion on disease severity index values. Part II: using the disease severity index for null hypothesis testing," Annals of Applied Biology, vol. 171, no. 3, pp. 490-505, 2017.

[41] S. Cho, J.-W. Jang, S.-H. Jung, B. R. Lee, E. Oh, and K.-H. Lee, "Precursor effects of citric acid and citrates on $\mathrm{ZnO}$ crystal formation," Langmuir, vol. 25, no. 6, pp. 3825-3831, 2009.

[42] V. R. Venu Gopal and S. Kamila, "Effect of temperature on the morphology of $\mathrm{ZnO}$ nanoparticles: a comparative study," Applied Nanoscience, vol. 7, no. 3-4, pp. 75-82, 2017.

[43] S. Ahmed, S. A. Annu, and S. Chaudhry, "A review on biogenic synthesis of $\mathrm{ZnO}$ nanoparticles using plant extracts and microbes: A prospect towards green chemistry," Journal of Photochemistry and Photobiology B: Biology, vol. 166, pp. 272-284, 2017.

[44] P. Mishra, Y. P. Singh, H. P. Nagaswarupa et al., "Caralluma fimbriata extract induced green synthesis, structural, optical and photocatalytic properties of $\mathrm{ZnO}$ nanostructure modified with Gd," Journal of Alloys and Compounds, vol. 685, pp. 656-669, 2016.

[45] C. A. Soto-Robles, P. A. Luque, C. M. Gómez-Gutiérrez et al., "Study on the effect of the concentration of Hibiscus sabdariffa extract on the green synthesis of $\mathrm{ZnO}$ nanoparticles," Results in Physics, vol. 15, p. 102807, 2019.

[46] R. A. Hess, B. J. Moore, J. Forrer, R. E. Linder, and A. A. AbuelAtta, "The fungicide benomyl (methyl 1-(butylcarbamoyl)-2benzimidazolecarbamate) causes testicular dysfunction by inducing the sloughing of germ cells and occlusion of efferent ductules," Fundamental and Applied Toxicology, vol. 17, no. 4, pp. 733-745, 1991.

[47] V. Muthuviveganandavel, P. Muthuraman, S. Muthu, and K. Srikumar, "Toxic effects of carbendazim at low dose levels in male rats," The Journal of Toxicological Sciences, vol. 33, no. 1, pp. 25-30, 2008.

[48] M. Axelstad, J. Boberg, C. Nellemann et al., "Exposure to the widely used fungicide mancozeb causes thyroid hormone disruption in rat dams but no behavioral effects in the offspring," Toxicological Sciences, vol. 120, no. 2, pp. 439-446, 2011.

[49] L. M. Domico, G. D. Zeevalk, L. P. Bernard, and K. R. Cooper, "Acute neurotoxic effects of mancozeb and maneb in mesencephalic neuronal cultures are associated with mitochondrial dysfunction," Neurotoxicology, vol. 27, no. 5, pp. 816-825, 2006.

[50] S. Srivastava, C. Kadooka, and J. Y. Uchida, "Fusarium species as pathogen on orchids," Microbiological Research, vol. 207, pp. 188-195, 2018.

[51] S. C. De la Rosa-García, P. Martínez-Torres, S. Gómez-Cornelio, M. A. Corral-Aguado, P. Quintana, and N. M. GómezOrtíz, "Antifungal activity of $\mathrm{ZnO}$ and $\mathrm{MgO}$ nanomaterials and their mixtures against Colletotrichum gloeosporioides strains from tropical fruit," Journal of Nanomaterials, vol. 2018, 2018.

[52] N. Pariona, F. Paraguay-Delgado, S. Basurto-Cereceda, J. E. Morales-Mendoza, L. A. Hermida-Montero, and A. I. MtzEnriquez, "Shape-dependent antifungal activity of $\mathrm{ZnO}$ 
particles against phytopathogenic fungi," Applied Nanoscience, vol. 10, no. 2, pp. 435-443, 2020.

[53] J. I. García-López, G. Niño-Medina, E. Olivares-Sáenz et al., "Foliar application of zinc oxide nanoparticles and zinc sulfate boosts the content of bioactive compounds in habanero peppers," Plants, vol. 8, no. 8, p. 254, 2019.

[54] D. Del Buono, A. Di Michele, F. Costantino, M. Trevisan, and L. Lucini, "Biogenic $\mathrm{ZnO}$ nanoparticles synthesized using a novel plant extract: application to enhance physiological and biochemical traits in maize," Nanomaterials, vol. 11, no. 5, p. 1270, 2021.

[55] M. Adrees, Z. S. Khan, M. Hafeez et al., "Foliar exposure of zinc oxide nanoparticles improved the growth of wheat (Triticum aestivum L.) and decreased cadmium concentration in grains under simultaneous Cd and water deficient stress," Ecotoxicology and Environmental Safety, vol. 208, article 111627, 2021.

[56] M. Kolenčík, D. Ernst, M. Komár et al., "Effect of foliar spray application of zinc oxide nanoparticles on quantitative, nutritional, and physiological parameters of foxtail millet (Setaria italica L.) under field conditions," Nanomaterials (Basel), vol. 9, no. 11, article 1559, 2019.

[57] A. Rastogi, M. Zivcak, O. Sytar et al., "Impact of metal and metal oxide nanoparticles on plant: a critical review," Frontiers in Chemistry, vol. 5, p. 78, 2017.

[58] V. L. Reddy Pullagurala, I. O. Adisa, S. Rawat et al., "Finding the conditions for the beneficial use of $\mathrm{ZnO}$ nanoparticles towards plants-a review," Environmental Pollution, vol. 241, pp. 1175-1181, 2018. 